\title{
MedDRA Preferred Term Code
}

National Cancer Institute

\section{Source}

National Cancer Institute. MedDRA Preferred Term Code. NCI Thesaurus. Code

C117056.

A coded value specifying the preferred term from the Medical Dictionary for Regulatory Activities (MedDRA). 